\title{
PSP Measurement of the Jet Impingement Flow Field over a Flat Plate.
}

\section{Kazuyoshi TOMOCHIKA, Naozo HATTORI, Masashi MATSUMOTO} Nobuyuki TSUBOI, Nobuyosi FUJIMATSU and Kozo FUIII

\begin{abstract}
The pressure sensitive paint (PSP) has recently received wide attention as a revolutionary new optical pressure measurement scheme. The objective of the present work is to show the feasibility of PSP as a measurement tool of jet impingement flow fields. The results show that the large difference of the wall static temperature leads to nonphysical results. The key points necessary for the reliable measurements is thermal diffusively to keep uniform wall temperature.
\end{abstract}

Keywords: Pressure Sensitive Paint, Jet Impingement, Wall Static Pressure, Temperature Effect

1. 緒言

通常の流体力学実験において模型表面上の圧力分布を 求めるためには, 模型表面にいくつかの圧力孔を設け, 圧 カセンサを用いて計測する方法が一般的であった。 しか し, 測定面に設置できる圧力孔の数には構造的にも限界 があり，たとえば翼端のように形状が極端に薄くなる場 所では圧力孔を加工できないなどといった問題点があっ た. また, 従来の圧力孔を用いた計測では, あらかじめ模 型に設置した圧力孔の位置以外に存在する衝撃波や剥離 等の急激な圧力変化を計測することはできなかった。

一方，近年全く新しい圧力計測手法として注目されて いる, 感圧塗料 (PSP : Pressure Sensitive Paint)は, 面情報として詳細な圧力分布を計測することが可能であ る.さらに, PSPでは模型寸法・形状に制限はなく, 光学 系を設置できれば圧力を計測することができるため，航 空工学の分野を中心に研究・開発が進められてきた。. ${ }^{(1)-(8)}$

また, PSPは衝撃波の干渉によって形成される複雑な流 れ場においても面計測が可能である. そのため, ロケット の分離時等で問題になっている三次元衝突噴流における 壁面圧力分布が詳細に計測できると期待される. しかし ながら,これまでの計測手法とは異なる手法であるため, 計測手法やデータ処理手法が十分確立されておらず, 計 測精度など不明な点も残されている。

そこで, 衝突噴流によって生じる複雑な圧力分布のPSP による計測を試み, その問題点の把握した.

\section{2. 実験装置}

実験には宇宙科学研究所の小型吸い込み式風洞を用い た. 風洞はノズル, 測定部, 真空チャンバにより構成され
るが,ノズルは円錐型先細ノズルで, 出ロマッ八数を 1 と した. 測定部は衝突平板およびその変角装置と可視化空 からなり，流れ場を確認するためのシュリーレン計測と PSP計測が同時に行える様になっている. 衝突平板はノズ ル出口直径 $(\phi 5 \mathrm{~mm})$ に比べて十分大きく $(\square 200 \times 200 \mathrm{~mm})$ ，

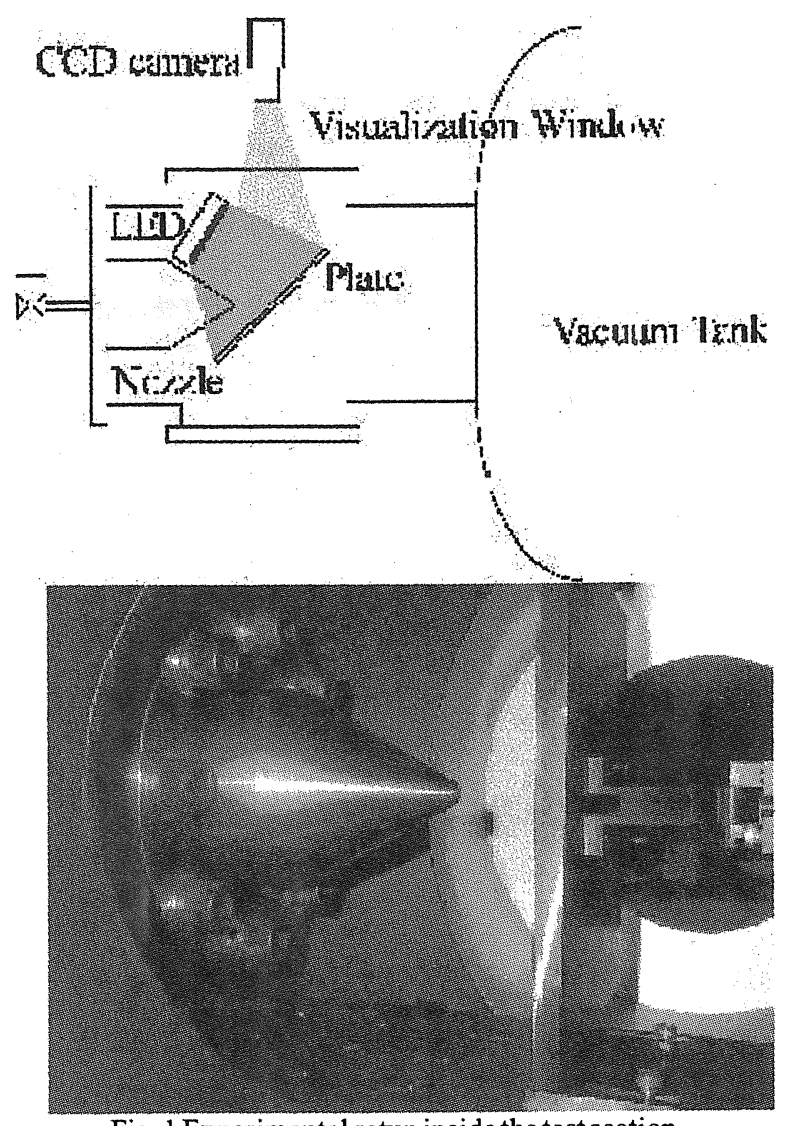

Fig. 1 Experimental setup inside the test section. 
友近一善, 服部直三，友近一善，服部直三，松本尚之，坪井伸幸，藤松信義，藤井孝藏
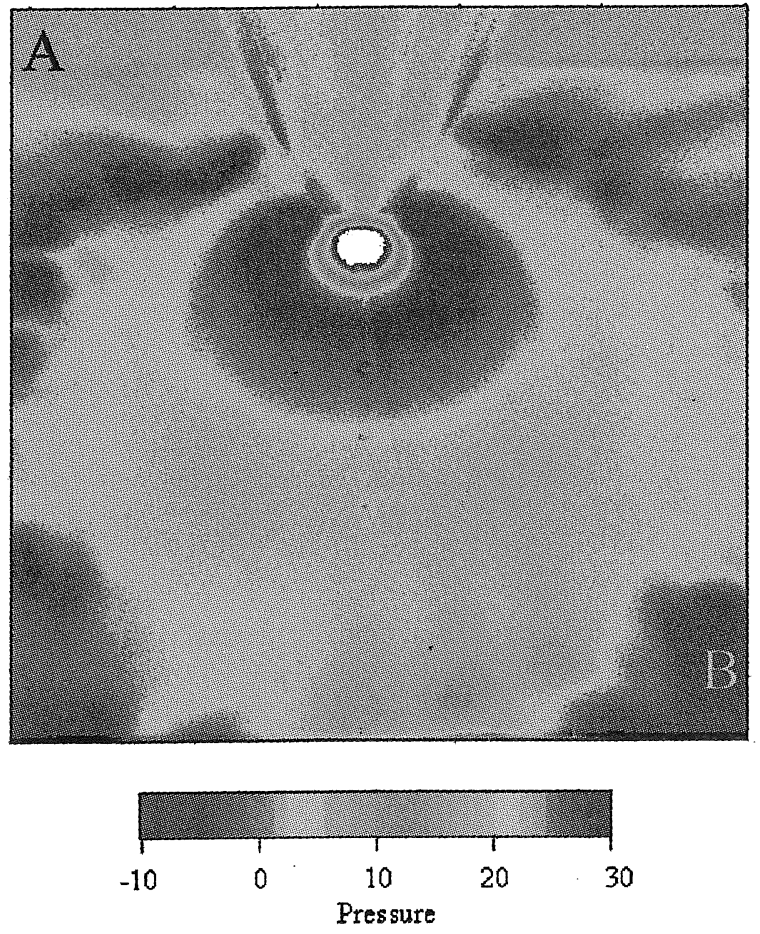

Fig. 2 Pressure distributions with Ru(bpy)+TLC plate at Ps/ $\mathrm{Pb}=129$.

衝突噴流が周辺部と干渉することはない，平板には数点 の静压孔が設けられ，PSP 計測時のin situ較正用データ を取得した。

PSP 計測用の励起光源としては青色LED（日覀化学 NSPB300A：中心波長 $460 \mathrm{~nm} ） を 222$ 個並べたものを 2 個， 108 個並べたものを 1 個, 真空チャンバの中に設置し, 直 接PSPを励起できるようにした。. ${ }^{(9)-(10)}$

PSP 色素には励起波長が青色 LED の発光波長に近いル

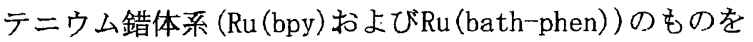
使用し，TLCシート（シリカゲル60）もしくはアルミ酸 化皮膜を吸着層として用いた. PSP色素はメチルアルコー ルもしくはジクロロメタンを溶媒として，およそ $1000 \mathrm{ppm}$ 程度のPSP 溶液を作成した。作成したPSP 溶液 に, 吸着層（TLCシートもしくはアルミ酸化皮膜）を浸 し, その後自然乾燥した.

PSPから放射される信号光は, シャープカットフィルタ を用い励起光を除去した後, CCD カメラ（浜松ホトニク 又製 C4742-95-12NR：解像度 $1024 \times 1024 \times 12 b i t$ 階調）で 撮影した。

今回はPSP計測の課題を明らかにすることを目的とした ので, 衝突平板角度 $\alpha=45^{\circ}$, ノズル出ロー平板間距離 $\mathrm{X}_{\mathrm{np}}$ ! $\mathrm{R}_{\mathrm{n}}=4\left(\mathrm{X}_{\mathrm{np}}\right.$ : ノズルー平板間距離, $\mathrm{R}_{\mathrm{n}}$ : ノズル出口半径) に 固定して実験を行った. また, 実験中に気流全圧を変更す ることにより圧力比 $\mathrm{Ps} / \mathrm{Pb}$ ( $\mathrm{Ps}$ : ノズル出口静圧, $\mathrm{Pb}$ : 背

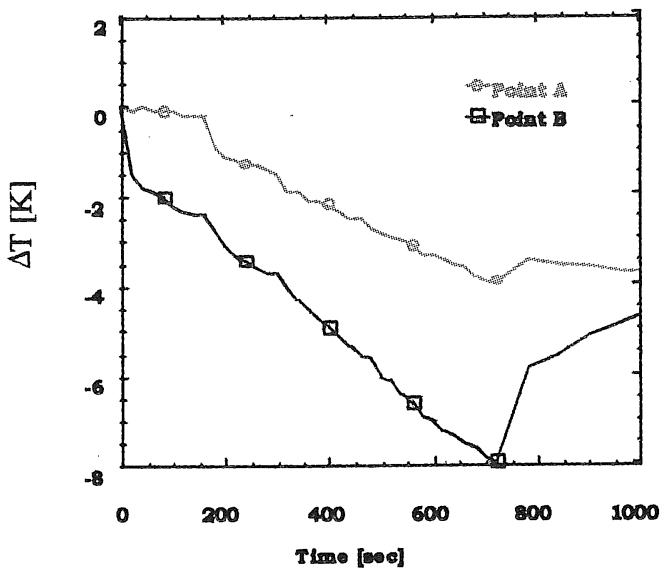

(a)Temperature change.

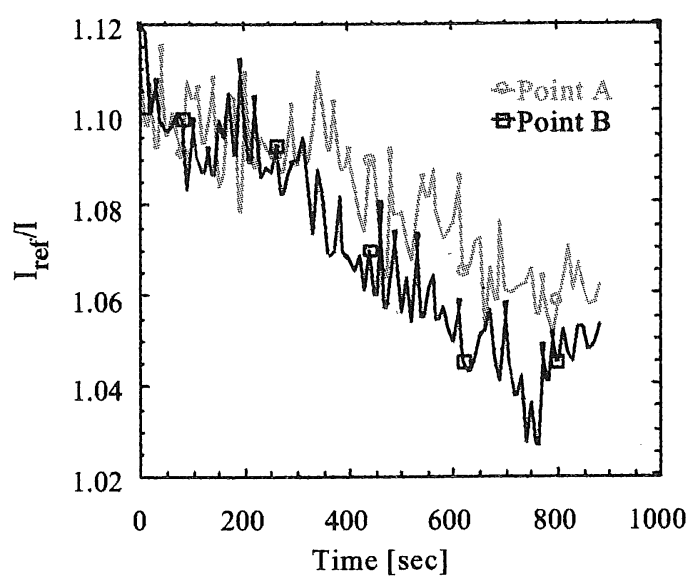

(b) Intencity ratio change.

Fig. 3 Intencity ratio and temperature change with $\mathrm{Ru}$ (bpy) + TLC plate at $\mathrm{Ps} / \mathrm{Pb}=129$.

圧）を変更した。

\section{3. 実験結果}

Fig. 2 にPSP (Ru (bpy) + TLCシート) で求めた衝突平 板上の圧力分布を示す. 通風時間は0〜 700秒である.Fig. 2では圧力を絶対圧で表しているが, 局所的に負の圧力を 示寸など，物理的におかしくなるほど計測誤差が含まれ ている.PSPの誤差を増大する原因として, 温度の影響で 発光輝度が変化することが知られている. 特にこれまで の研究からルテニウム錯体は温度依存性が強いことが報 告されており(11)，1Kの温度変化で発光輝度が $1 \sim 2 \%$ 変化 すると考えられる。

そこで，温度の影響を確認するためにFig. 2 に示すA 点 (左上), B 点 (右下) の温度変化と PSP信号光の輝度 
比変化をFig. 3 に示す. 実験では常温の大気を真空チャ ンバに吸い込むことにより音速噴流を作り出しているた め, 気流は断熱膨張のため, きわめて低温となる. 気流成 立後, 平板は低温の気流にさらされるため, 温度が低下す るが，衝突噴流の構造から場所により熱流束が異なる.

PSP色素の吸着層として用いているTLCシートは, 吸着 剂として多孔質のシリカゲルを用いており, 熱伝導率は あまり高くない，しかし，母材はアルミであり，TLCシー トをアルミ製の衝突平板に添付しているので, 気流と平 板の間の熱伝達よりアルミ内の熱伝導の方が大きいと考 えて, 温度分布は無視していた. しかし, 今回の実験の様 に, 実験時閒が数百秒と長時閒にわたると温度伝遒度の 問題から, 平板内に温度分布が生じたものと思われ，それ が計測誤差の原因となったと考えられる.

いま, $\mathrm{A}$ 点と $\mathrm{B}$ 点で実験開始後 700 秒での温度差は約 $3.9 \mathrm{~K}$ であるが，このときの輝度比差は約 0.04 であり，ほ ぼ温度差分の違いが䛊差となっていると推定される.

そこで, 衝突平板内に温度差が生じないように, 衝突平 板を厚さ $10 \mathrm{~mm}$ のアルミで製作し，表面を酸化皮膜処理す ることによって，直接PSP色素を吸着できるようにした， この場合の A点およびB 点の温度低下の時閒変化をFig. 4 (a)に示す. 通風時閒は $0 \sim 700$ 秒である.TLCシートの 場合と異なり温度伝導度が大きいため，平板上で温度差 は最大でも約 $0.7 \mathrm{~K}$ であり, 非常に小さい. 発光輝度変化 をFig. 4(b)に示す. 熱流束を変化させるために圧力比を 変化させても発光輝度比にほとんど差が生じていない， このことから，平板内で温度分布がつかない限り, in situ較正で正しい圧力分布が求められると考えられる.

この温度伝導度の大きなPSP 色素吸着層を用いて計測 した圧力分布をFig. 5 に示す. TLCプレートを吸着剤と して用いた場合と異なり，負の絶対圧を示す領域は現れ ていない、マッハディスクや噴流境界が壁面と干渉する ことによって生じる複雑な圧力場が可視化できており, 画像中央部分には三日月状の高圧領域が確認された.

同条件におけるシュリーレン写真をFig. 6に示す.PSP により可視化された高圧部はシュリーレン写真から計測 された衝撃波の入射位置とほぼ一致しており，十分な精 度で圧力分布が計測できていることがわかる。

これらの結果から, 測定面における温度の均一性を保 証すれば, ルテニウム錯体の様な温度依存性の高いPSP色 素を用いても，精度よく压力分布を計測できることがわ かった.

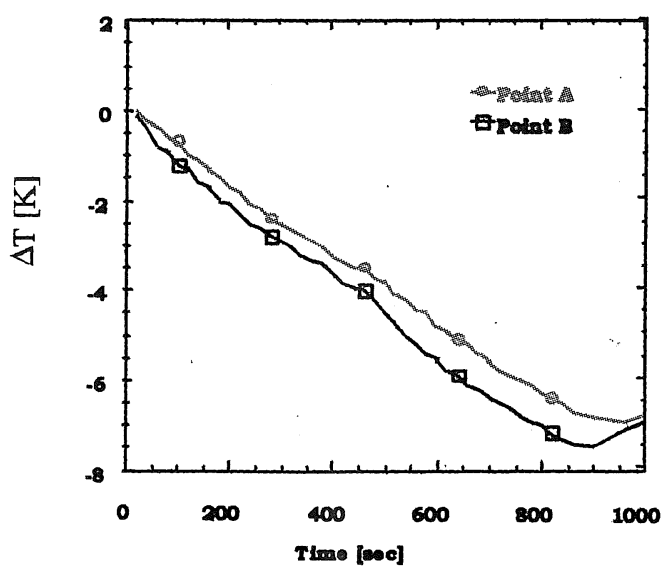

(a) Temperature change at $\mathrm{Ps} / \mathrm{Pb}=125$.

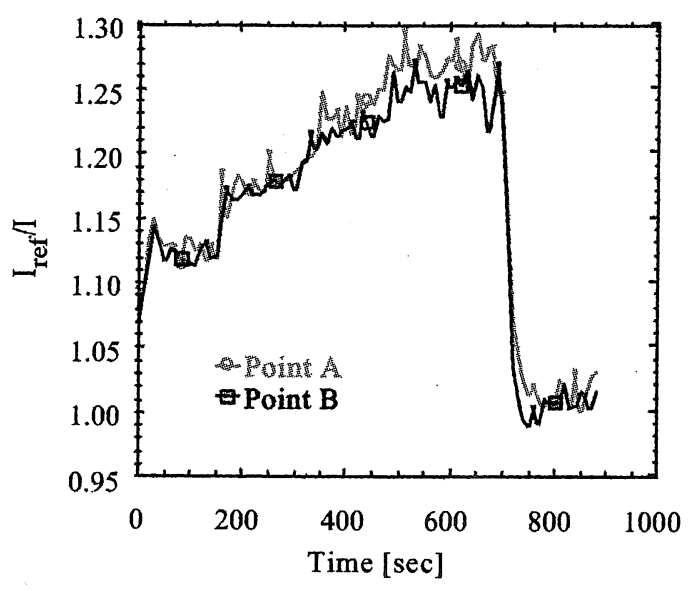

(b) Intencity ratio change at $\mathrm{Ps} / \mathrm{Pb}=125$.

Fig. 4 Traces of Intencity ratio and temperature change with Ru(bath-phen)+anodized aluminum.

4.まとめ

三次元衝突噴流による衝突平板上の圧力分布をPSPを用 いて可視化した. その結果次のことが明らかになった.

（1）数百秒にわたる様な長時間の計測を実施すると, 圧 力計測誤差が大きくなる．測定自に温度分布がついた場 合，PSPの持つ温度依存性の影響が大きくなるためである と考えられる.

（2）測定面における温度の均一性を保証すれぱ,ルテニ ウム錯体の様な温度依存性の高いPSP色素を用いても, 十 分な精度で圧力分布を計測することが可能であると考え られる。 
友近一善, 服部直三，友近一善，服部直三，松本尚之，坪井伸幸，藤松信義，藤井孝藏
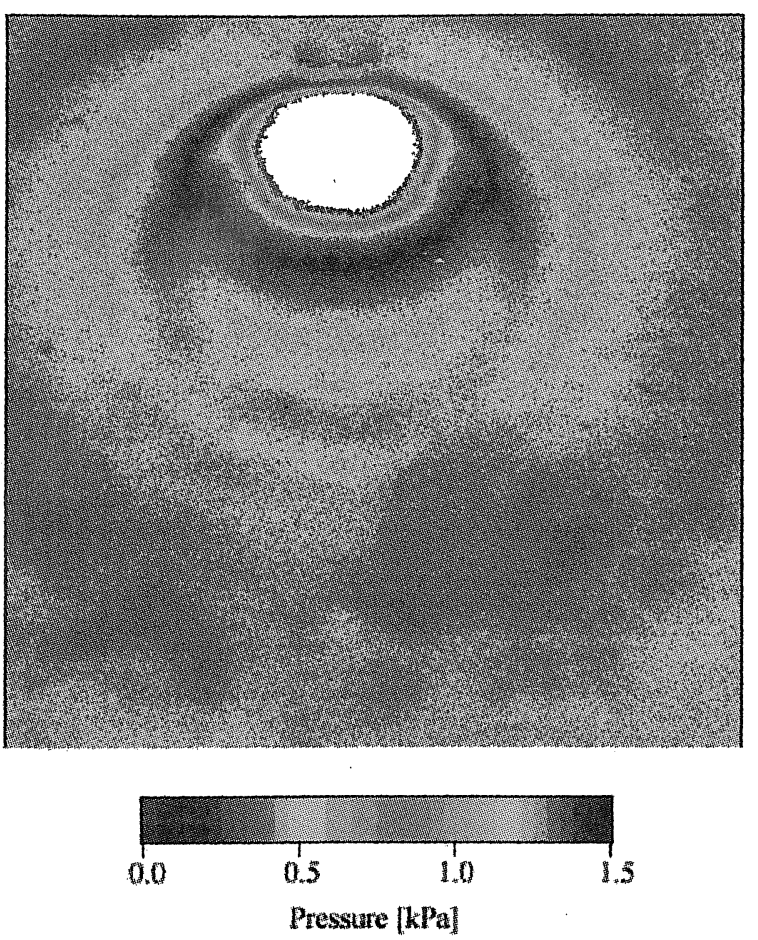

Fig.5Pressure distribution with Ru(bath-phen)+anodized aluminium at $\mathrm{Ps} / \mathrm{Pb}=125$.

\section{5. 謝辞}

本研究の一部は, 文部科学省科学技術振興調整費「機能 性分子による熱流体センシング技術の研究開発 (MOSAIC) の元に，航空宇宙技術研究所からの受託研究として行わ れた.

\section{参考文献}

(1)R. H. Engleretal. , Descriptionandassessment of anewoptical pressure measurement system (OPMS) demonstrated in the high speed wind tunnel of DLR in Gottingen. DLR-FB 92-21 (1992)

(2)R. C. Crites, Pressuresensitivepainttechnique, vonKarmanInstitute forFluidDynamicLectureSeries 1993-05 (1993)

(3)'宮里義昭他,ショッケチェーブを用いた感圧染料の過渡応答に関する実

験,平成 9 年度衝慗波ンルボジ方講演論文集(1998), pp. 19-22

(4) Handa, T. atel. , Experimental investigationonluminescentcharacteristicsof fastrespondingpressuresensitivepaint. Proceedingso [ the 2nd Pacific Symposium on Flow Visual ization and Image Processing. (1999) PF087

（5）坂村芳莪他,感圧塗料による時間分解圧力計測,第 32 回流体 力学講演会

(6)松本尚之他,感圧塗料による非定常圧力部测, 日本機械学会流 体工学部門2000年講演会

(7) Hallard, R. et al., Aerospike nozzle tests. 3rd Sympo-

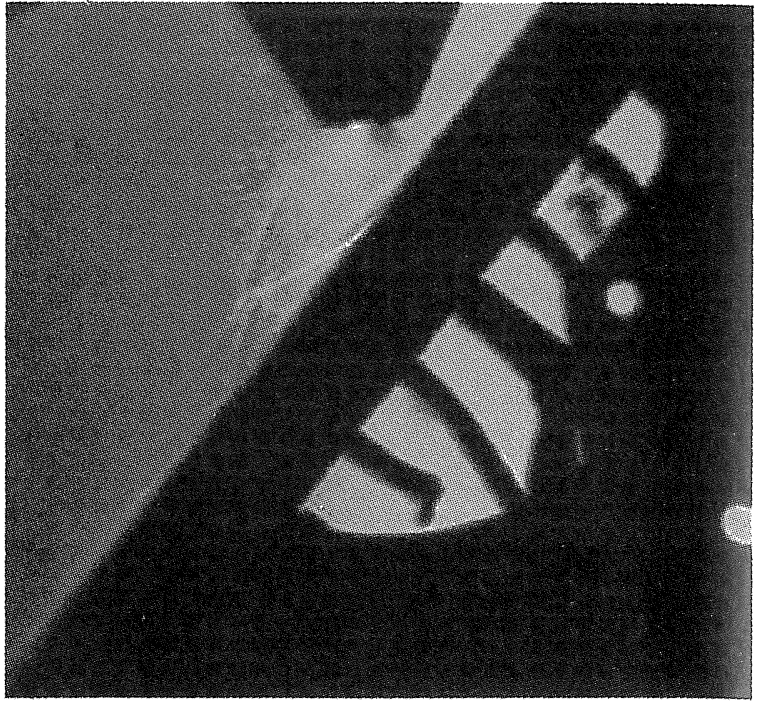

Fig.6Schlierenphotographat $\mathrm{Ps} / \mathrm{Pb}=125$.

sium on Aerothermodynamics for Space Vehicles, TP 1998220 (1998)

(8) Mebarki, Y. et al., PSP application of a supersonic aerospike nozzle. PSP Workshop, TP 1999-41 (1998)

(9) Clinehens, G. $\Lambda$. U1trastable blue-LED illumination sources for PSP Applications.

（10）寺木進他 発光ダイオードを用いた感圧塗料による壁面圧力 測定の試み, 平成11年度宇宙輸送シンポジウム (2000)

(11) Gallery, J. . L. Luminescence imaging for aerodynamic temperature andpressuremeasurements. Doctoral Thesis, Universityof Washington ChemistryDepartment (1993) 